\title{
Atributos físicos de um Latossolo Vermelho e produtividade de culturas cultivadas em sucessão e rotação
}

\author{
Physical properties of an Oxisol and crops yield under succession and rotation
}

\author{
Silvio Aymone Genro Junior ${ }^{\mathrm{I}}$ Dalvan José Reinert ${ }^{\mathrm{II}}$ José Miguel Reichert $^{\mathrm{II}}$ \\ Jackson Adriano Albuquerque ${ }^{\mathrm{III}}$
}

RESUMO

Este estudo objetivou avaliar os efeitos da sucessão e rotação de culturas nos atributos físicos e na produtividade dos cultivos agrícolas de um Latossolo Vermelho sob plantio direto, localizado no Estado do Rio Grande do Sul. Os tratamentos contaram de quatro seqüências de culturas cultivadas de 1998 a 2001: 1) sucessão trigo / soja; 2) rotação milho / aveia / milho+guandu anão / trigo / soja / trigo; 3) rotação guandu anão / trigo / soja / trigo / soja / aveia; e 4) rotação crotalária / trigo / soja / aveia / milho / trigo. Em outubro de 2000 e de 2001, foram coletadas amostras de solo para determinar os atributos físicos do solo. Em todas as safras foi medida a produtividade das culturas. O Latossolo Vermelho cultivado com plantio direto apresenta um grau de compactação elevado, com densidade do solo acima e volume de macroporos abaixo do limite crítico para a classe textural muito argiloso. As maiores limitações ocorrem abaixo da camada de 0 a $0,03 m$, pois na camada mais superficial, apesar das pressões exercidas, a mobilização do solo nas operações de semeadura e adubação em linha aumenta a porosidade e reduz a densidade do solo. Nessa camada, houve maior volume de poros entre a saturação e a capacidade de campo, responsáveis pela aeração do solo, e entre a capacidade de campo e o ponto de murcha permanente, responsáveis pelo armazenamento da água disponível para as plantas. A introdução de plantas de cobertura a cada três anos não foi eficiente para reduzir a compactação. A produtividade das culturas foi influenciada positivamente na rotação com crotalária, enquanto os demais sistemas não diferiram da sucessão de culturas.

Palavras-chave: estrutura do solo, compactação do solo, curva de retenção de água.

\begin{abstract}
This study had as objective to evaluate the effects of crops succession and rotation on physical properties and crops yield on an Oxisol (clayey Haplortox) under no-tillage system, in Rio Grande do Sul State, Brazil. The treatments included four cropping sequences, used from 1998 to 2001: 1) succession wheat / soybean, 2) rotation corn / oat / corn+ Cajanus cajan L. Millsp / wheat / soybean / wheat, 3) rotation Cajanus cajan L. Millsp / wheat / soybean / wheat / soybean / oat, and 4) rotation Crotalaria juncea L. / wheat / soybean / oat / corn / wheat. In October of 2000 and 2001, soil samples were collected to determine physical properties. In all years, the crops yield was measured. The Oxisol cultivated under notillage had a high compaction degree, with soil bulk density greater and macroporosity smaller than the critical limit for clay texture. The largest limitations were observed below the layer of 0 to $0,03 \mathrm{~m}$, because in the uppermost layer soil mobilization by successive operations of fertilization and sowing increases soil porosity and reduces soil density. Thus, greater volume of pores is observed between soil saturation and field capacity, responsible for soil aeration, and between field capacity and wilting point, responsible for storage of plant available water. The use of cover crops once every three years was not efficient to reduce soil compaction. The yield of the subsequent crops was influenced positively in the rotation with Crotalaria juncea, while the other cropping systems did not differ from crop succession.
\end{abstract}

Key words: soil structure, compaction, water retention curve.

IEstação Experimental do Arroz, convênio Instituto Riograndense do Arroz/Cooperativa Agrícola Alegretense. Cachoeirinha, RS, Brasil. E-mail: silvio-genro@irga.rs.gov.br.

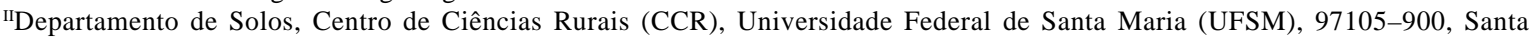
Maria, RS. E-mail: dalvan@smail.ufsm.br. *Autor para correspondência.

IIIDepartamento de Solos, Centro de Ciências Agroveterinárias, Universidade do Estado de Santa Catarina. 


\section{INTRODUÇÃO}

A compactação é caracterizada pela redução do volume de poros e da taxa de difusão de oxigênio e aumento da densidade da resistência física e da energia com que a água é retida no solo (MÜLLER et al., 2001). Em solos não cultivados, a compactação em grau moderado pode aumentar a disponibilidade de água para as culturas (ROSENBERG, 1964). No entanto, com grau elevado, a disponibilidade pode ser menor pela diminuição do volume de poros capilares (VEIHMEYER \& HENDRICKSON, 1948). Assim, a compactação é um processo importante, principalmente quando atinge limites críticos, ou seja, quando diminui a quantidade de água disponível e prejudica o crescimento radicular, confinando as raízes acima da camada compactada ou em partes do perfil (UNGER \& KASPAR, 1994). Isso diminui o volume de solo explorado pelas raízes, a quantidade de ar, água e nutrientes disponíveis e limita a produtividade das culturas (MORAES et al., 1995). O grau de compactação é dependente do sistema de manejo do solo utilizado, que reflete a intensidade de preparo e a espessura da camada mobilizada, e do histórico de uso, como as pressões exercidas, a umidade no momento das operações de cultivo e o número de passadas dos equipamentos em cada safra (SECCO et al., 2004).

No sistema de plantio direto, muitos benefícios têm sido relatados, principalmente no controle da erosão hídrica, no acúmulo de matéria orgânica e de nutrientes no solo (BAYER et al., 2000). Entretanto, geralmente, os solos são compactados abaixo da camada superficial, independente do teor de argila (REICHERT et al., 2003, 2008), sendo considerada uma conseqüência normal desse sistema (SILVA et al., 2000). Para preservar a qualidade do solo e eliminar a necessidade de mobilizações nesse sistema, é recomendado o uso da rotação de culturas, a qual diminui a densidade e aumenta a porosidade, a condutividade hidráulica saturada e a estabilidade de agregados do solo, conforme constatado por ALBUQUERQUE et al. (1995) e CAMPOS et al. (1995), em Latossolo Vermelho distrófico argiloso, e por WOHLENBERG et al. (2004), em Argissolo VermelhoAmarelo.

Em Latossolo Vermelho distroférrico, cultivado sob plantio direto e rotação de culturas, SECCO et al. (2004) observaram que níveis elevados de compactação prejudicaram os atributos físicos do solo, mas não a produtividade da soja. ABREU et al. (2004) observaram prejuízos da compactação nas propriedades hídricas de um Argissolo franco arenoso, mas o cultivo da crotalária aumentou a condutividade hidráulica, a infiltração e o armazenamento de água no solo. Em contrapartida, COSTA et al. (2003), em Latossolo Bruno alumínico cultivado por 21 anos sob plantio direto com rotação de culturas, não observaram os sintomas da compactação. Além disso, CÂMARA \& KLEIN (2005) observaram que a escarificação de um Latossolo Vermelho Distrófico muito argiloso que estava sendo cultivado no sistema de plantio direto reduziu a densidade, mas a produtividade da soja não diferiu do plantio direto não escarificado. Resultados semelhantes foram observados na cultura do feijão em Argissolo Vermelho distrófico arênico (COLLARES et al., 2006). Isso sugere que o grau de compactação não havia alcançado um estado crítico que reduzisse o crescimento e a produtividade das culturas, ou que, embora compactado, o plantio direto apresenta propriedades que compensam a compactação, como, por exemplo, poros contínuos formados pelos cultivos anteriores, conforme discutido em BOUMA (1991).

O objetivo deste estudo foi avaliar os efeitos da sucessão e rotação de culturas nos atributos físicos e na produtividade das culturas de um Latossolo Vermelho distroférrico sob plantio direto.

\section{MATERIAL E MÉTODOS}

O experimento foi desenvolvido na COTRIJUÍ, no município de Ijuí, Rio Grande do Sul (RS). O clima do município é Cfalg ${ }^{2}$, conforme a classificação de Köppen. A temperatura média do mês mais quente é superior a $22^{\circ} \mathrm{C}$ e do mês mais frio fica entre 3 e $18^{\circ} \mathrm{C}$. A precipitação média anual é superior a $1.600 \mathrm{~mm}$, com maior precipitação na primavera e no verão. O solo é Latossolo Vermelho distroférrico típico muito argiloso (EMBRAPA, 2006).

Até o inverno de 1998, a área foi manejada sob o sistema de preparo convencional, com cultivos de milho (grão e silagem), soja, trigo e aveia branca. De 1998 a 2001, o experimento foi realizado no delineamento inteiramente casualizado, com quatro repetições e parcelas de $150 \mathrm{~m}^{2}$. Os tratamentos implantados no sistema de plantio direto foram: 1) sucessão de duas culturas, trigo/soja (S-TS); 2) rotação com cinco culturas, milho / aveia / milho+guandu / trigo / soja / trigo (R-MAGTS); 3) rotação com quatro culturas, guandu / trigo / soja / trigo / soja / aveia (R-GTSA); e 4) rotação com cinco culturas, crotalária / trigo / soja / aveia / milho / trigo (R-CTSAM). Os sistemas de rotação incluem um cultivo de aveia seguido pelo milho semeado no cedo e posterior inclusão de uma leguminosa de verão, guandu anão (Cajanus cajan) e crotalária (Crotalária spp.) a cada três anos. O manejo das culturas seguiu as recomendações técnicas para a região.

Ciência Rural, v.39, n.1, jan-fev, 2009. 
Amostras de solo foram coletadas em outubro de 2000 em um perfil aberto para cada parcela. Com estrutura alterada, foram coletadas $(0 \mathrm{a} 0,10 ; 0,10$ a 0,20 e 0,20 a $0,40 \mathrm{~m}$ ) amostras para determinação da granulometria pelo método da pipeta, da densidade de partículas pelo método do balão volumétrico (EMBRAPA, 1997), dos limites de plasticidade e de liquidez, do índice de plasticidade (Limites de Atterberg) (SOWERS, 1965) e de propriedades químicas (TEDESCO et al., 1995), com três repetições de laboratório (Tabela 1). Com estrutura preservada, foram coletadas ( 0 a 0,03, 0,10 a 0,13 e 0,20 a 0,23m), amostras em anéis metálicos com $0,053 \mathrm{~m}$ de diâmetro e $0,03 \mathrm{~m}$ de altura, para determinar a densidade e porosidade do solo, com duas repetições de campo por parcela. As amostras foram saturadas e submetidas às tensões de 1 e $6 \mathrm{kPa}$ em mesa de tensão, de 33, 100, 300 e 500kPa em câmara de Richards, e entre 33 e 1500kPa em psicrômetro de termopar (KLEIN et al., 2006). Aos pares de dados de tensão e de umidade volumétrica, foi ajustada a equação de Van Genuchten (1980), e posteriormente foi calculada a distribuição de diâmetros de poros, obtendo-se as classes com diâmetro maior que $50 \mu \mathrm{m}$, entre 50 e $4,4 \mu \mathrm{m}$ e menor que $4,4 \mu \mathrm{m}$, relacionadas com a tensão aplicada, utilizando a equação da capilaridade. O teor de água disponível (AD) foi obtido pela diferença entre a água retida a $10 \mathrm{kPa}$ e a $1500 \mathrm{kPa}$. A condutividade hidráulica saturada foi medida no campo, em outubro de 2001, em três locais por parcela, até atingir vazão constante, com permeâmetro de Guelph (ELRICK et al.,
1987), em um poço de $0,15 \mathrm{~m}$ de profundidade e aplicação de uma carga hidráulica de 0,10m.

A matéria seca da parte aérea do guandu anão, da crotalária e da aveia foi determinada na plena floração. A produtividade de grãos foi determinada quando as culturas estavam aptas para a colheita, e expressa para umidade do grão de $13 \%$. Os dados foram submetidos à análise da variância, aplicando-se o teste F, para um delineamento em blocos ao acaso. A comparação das médias entre os sistemas de culturas em cada camada de solo foi realizada por meio de três contrastes ortogonais: 1: S-TS x R-MAGTS: R-GTSA: R-CTSAM (1 x 2:3:4); contraste entre o sistema com sucessão versus os sistemas com rotação de culturas; 2: R-MAGTS x R-GTSA ( 2 x 3); contraste entre as rotações com guandu no quarto ciclo versus guandu no primeiro ciclo; 3: R-GTSA x R-CTSAM ( $3 \times 4$ ); contraste entre as rotações com guandu versus crotalária, ambas implantadas no primeiro ciclo. As médias entre camadas foram discutidas por meio de comparações relativas.

\section{RESULTADOS E DISCUSSÃO}

Os contrastes indicam que os sistemas de sucessão e rotação não influenciaram os atributos físicos relacionadas com a densidade e porosidade do solo. A densidade do solo e os atributos relacionados à porosidade não variaram entre os sistemas em cada camada (Tabela 2). A porosidade total variou entre os

Tabela 1 - Atributos físicos e químicos em três camadas do Latossolo Vermelho. Ijuí, RS, 2000. Média de três repetições.

\begin{tabular}{|c|c|c|c|}
\hline \multirow{2}{*}{ Atributos } & \multicolumn{3}{|c|}{ Camadas } \\
\hline & 0 a $0,1 \mathrm{~m}$ & 0,1 a $0,2 \mathrm{~m}$ & 0,2 a $0,4 \mathrm{~m}$ \\
\hline Densidade de partículas, $\mathrm{Mg} \mathrm{m}^{-3}$ & 2,65 & 2,87 & 2,71 \\
\hline Areia grossa, $\mathrm{g} \mathrm{kg}^{-1}$ & 47 & 40 & 36 \\
\hline Areia fina, $\mathrm{g} \mathrm{kg}^{-1}$ & 65 & 64 & 60 \\
\hline Silte, $\mathrm{g} \mathrm{kg}^{-1}$ & 219 & 212 & 207 \\
\hline Argila, $\mathrm{g} \mathrm{kg}^{-1}$ & 671 & 685 & 698 \\
\hline Limite de liquidez & 41 & 41 & 43 \\
\hline Limite de plasticidade & 30 & 30 & 32 \\
\hline Índice de plasticidade & 12 & 11 & 12 \\
\hline Matéria orgânica, $\mathrm{g} \mathrm{kg}^{-1}$ & 33 & 21 & 25 \\
\hline $\mathrm{pH}\left(\mathrm{H}_{2} \mathrm{O}\right)$ & 4,9 & 5,2 & 5,0 \\
\hline Fósforo, mg L ${ }^{-1}$ & 21 & 3 & 5 \\
\hline Potássio, $\mathrm{mg} \mathrm{L}^{-1}$ & 200 & 26 & 80 \\
\hline Alumínio, $\mathrm{cmol}_{\mathrm{c}} \mathrm{L}^{-1}$ & 0,5 & 0,6 & 0,6 \\
\hline Cálcio, $\mathrm{cmol}_{\mathrm{c}} \mathrm{L}^{-1}$ & 4,4 & 4,1 & 3,7 \\
\hline Magnésio, $\mathrm{cmol}_{\mathrm{c}} \mathrm{L}^{-1}$ & 1,7 & 1,8 & 1,6 \\
\hline СТС а pH 7,0 & 12,2 & 10,6 & 10,6 \\
\hline Acidez potencial, $\mathrm{cmol}_{\mathrm{C}} \mathrm{L}^{-1}$ & 5,6 & 4,7 & 5,1 \\
\hline
\end{tabular}

Ciência Rural, v.39, n.1, jan-fev, 2009. 
Tabela 2 - Densidade do solo (DS), porosidade total (PT), microporosidade (Micro), macroporosidade (Macro) do solo e distribuição do tamanho de poros para diferentes sistemas de culturas e camadas no Latossolo Vermelho. Ijuí, RS, 2000.

\begin{tabular}{|c|c|c|c|c|c|c|c|c|}
\hline Camadas & Sistemas ${ }^{(1)}$ & DS & PT & Macro & Micro & P $4,4-50^{(2)}$ & P $0-4,4^{(3)}$ & Macro/PT \\
\hline $\mathrm{m}$ & & $\mathrm{Mg} \mathrm{m}^{-3}$ & $-\cdots$ & ------ & $-\mathrm{m}^{3} \mathrm{~m}^{-3}$ & ------- & --------- & \\
\hline \multirow[t]{4}{*}{0 a 0,03} & S-TS & $1,31^{(4)}$ & 0,64 & 0,18 & 0,46 & 0,12 & 0,34 & 0,28 \\
\hline & R-MAGTS & 1,27 & 0,64 & 0,18 & 0,46 & 0,13 & 0,33 & 0,28 \\
\hline & R-GTSA & 1,34 & 0,64 & 0,16 & 0,48 & 0,12 & 0,36 & 0,25 \\
\hline & R-CTSAM & 1,29 & 0,65 & 0,19 & 0,46 & 0,12 & 0,34 & 0,29 \\
\hline \multirow[t]{4}{*}{0,10 a 0,13} & S-TS & 1,52 & 0,58 & 0,08 & 0,50 & 0,10 & 0,39 & 0,14 \\
\hline & R-MAGTS & 1,48 & 0,60 & 0,11 & 0,49 & 0,10 & 0,39 & 0,18 \\
\hline & R-GTSA & 1,47 & 0,59 & 0,11 & 0,48 & 0,10 & 0,38 & 0,18 \\
\hline & R-CTSAM & 1,53 & 0,58 & 0,10 & 0,48 & 0,09 & 0,39 & 0,17 \\
\hline \multirow[t]{4}{*}{0,20 a 0,23} & S-TS & 1,47 & 0,60 & 0,10 & 0,50 & 0,11 & 0,39 & 0,17 \\
\hline & R-MAGTS & 1,45 & 0,59 & 0,11 & 0,48 & 0,10 & 0,38 & 0,18 \\
\hline & R-GTSA & 1,49 & 0,58 & 0,09 & 0,49 & 0,10 & 0,39 & 0,15 \\
\hline & R-CTSAM & 1,45 & 0,59 & 0,10 & 0,49 & 0,09 & 0,40 & 0,17 \\
\hline \multirow[t]{4}{*}{ Média } & S-TS & 1,43 & 0,61 & 0,12 & 0,49 & 0,11 & 0,38 & 0,20 \\
\hline & R-MAGTS & 1,40 & 0,60 & 0,13 & 0,47 & 0,11 & 0,36 & 0,21 \\
\hline & R-GTSA & 1,43 & 0,60 & 0,12 & 0,48 & 0,11 & 0,37 & 0,20 \\
\hline & R-CTSAM & 1,42 & 0,60 & 0,13 & 0,47 & 0,10 & 0,37 & 0,21 \\
\hline \multirow[t]{3}{*}{ Média } & 0 a 0,03 & 1,30 & 0,64 & 0,18 & 0,46 & 0,12 & 0,34 & 0,28 \\
\hline & 0,10 a 0,13 & 1,50 & 0,58 & 0,10 & 0,48 & 0,10 & 0,38 & 0,17 \\
\hline & 0,20 a 0,23 & 1,46 & 0,59 & 0,10 & 0,49 & 0,10 & 0,39 & 0,17 \\
\hline
\end{tabular}

(1) 1- S-TS - sucessão trigo/soja; 2- R-MAGTS - Rotação - milho/aveia/milho+guandu anão/trigo/soja/trigo; 3- R-GTSA - Rotação - guandu anão/trigo/soja/ trigo/soja/aveia; 4- R-CTSAM - Rotação - crotalária/trigo/soja/aveia/milho/trigo.

${ }^{(2)} \mathrm{P}$ 4,4-50 = poros com diâmetro entre 4,4 e $50 \mu \mathrm{m}$.

(3) $\mathrm{P} 0-4,4$ = poros com diâmetro entre 0 e $4,4 \mu \mathrm{m}$.

(4) Não houve efeito significativo dos sistemas de culturas nos atributos físicos do solo.

tratamentos de 0,60 a $0,61 \mathrm{~m}^{3} \mathrm{~m}^{-3}$, sendo composta por 0,47 a $0,49 \mathrm{~m}^{3} \mathrm{~m}^{-3}$ de microporos e 0,12 a $0,13 \mathrm{~m}^{3} \mathrm{~m}^{-3} \mathrm{de}$ macroporos. Dentre os microporos, de 0,10 a $0,11 \mathrm{~m}^{3} \mathrm{~m}^{-3}$ foram de diâmetro, entre 4,4 e $50 \mathrm{~mm}$ e de 0,36 a $0,38 \mathrm{~m}^{3} \mathrm{~m}^{-3}$ foram poros menores que 4,4mm (Tabela 2). Essa distribuição de tamanho de poros representa $21 \%$ de macroporos, $18 \%$ de poros entre 4,4 e 50mm e $61 \%$ menor que $4,4 \mathrm{~mm}$.

A densidade e porosidade demonstram que a qualidade física do Latossolo Vermelho está degradada. A densidade do solo nas camadas de 0 a 0,03, 0,10 a 0,13 e 0,20 a 0,23m foi, respectivamente, de 1,30, 1,50 e 1,46 $\mathrm{Mg} \mathrm{m}^{-3}$, valores na faixa considerada crítica para solos argilosos por VEIHMEYER \& HENDRICKSON (1948) e JONES (1983). Com base na teoria do intervalo hídrico ótimo, REICHERT et al. (2003, 2007) propuseram, para solos argilosos, que a densidade crítica varia de 1,30 a $1,40 \mathrm{Mg} \mathrm{m}^{-3}$ e, para solos muito argilosos, de 1,25 a 1,30 $\mathrm{Mg} \mathrm{m}^{-3}$. Quando a densidade de um Latossolo Vermelho muito argiloso superou 1,35 $\mathrm{Mg} \mathrm{m}^{-3}$, ALVARENGA et al. (1996) observaram restrições às raízes do guandu anão.

$\mathrm{O}$ aumento da densidade do solo nas camadas de 0,10 a 0,13 e 0,20 a 0,23m ocorreu às expensas da porosidade total e dos macroporos. Na primeira camada, não há restrição, mas abaixo de 0,10m a macroporosidade é crítica (XU et al., 1992), com menos de $0,10 \mathrm{~m}^{3} \mathrm{~m}^{-3}$ nos sistemas com sucessão S-TS e na rotação R-GTSA (Tabela 2). Em solos com baixa porosidade de aeração, as trocas gasosas diminuem e aumenta a concentração de gás carbônico, principalmente nas zonas compactadas, com prejuízo ao crescimento radicular. A relação ideal de macroporos em relação à porosidade total é de 0,33 , e indica a relação entre capacidade de aeração e retenção de água no solo. Não houve efeito dos sistemas de culturas, mas essa relação na primeira camada foi mais alta $(0,28)$ e de 0,10 a 0,13 e 0,20 a $0,23 \mathrm{~m}$ foi menor $(0,17)$. Constata-se que a porosidade total é composta principalmente por microporos, e a mobilização do solo para semeadura 
aumenta essa relação para próximo do ideal (OLNESS et al., 1998). Outra observação é que, na camada mais superficial, a microporosidade é composta principalmente por poros com diâmetro menor do que 4,4 $\mu \mathrm{m}$, responsáveis pela retenção de água, com volume de $0,34 \mathrm{~m}^{3} \mathrm{~m}^{-3}$, na camada de 0 a $0,03 \mathrm{~m}$, e $0,39 \mathrm{~m}^{3} \mathrm{~m}^{-3}$ nas demais (Tabela 2 ).

A menor densidade e a maior macroporosidade, observadas na camada superficial do solo manejado sob plantio direto, estão associadas às mobilizações que ocorrem nas operações de semeadura das culturas de verão e inverno. Considerando o espaçamento médio usado nas culturas de inverno de $0,17 \mathrm{~m}$ e que os mecanismos sulcadores para semeadura e adubação mobilizam uma camada de 0,05m ou mais, 30\% da área é mobilizada em uma única operação. Adicionando o efeito das culturas de verão e o cultivo sucessivo, em pouco tempo toda a camada superficial do solo sob plantio direto é mobilizada, enquanto que os efeitos das cargas se acumulam abaixo dessa camada. Ao avaliarem os atributos físicos de um Latossolo Vermelho eutroférrico, cultivado por 10 anos, nos sistemas plantio direto com escarificação $(0,30 \mathrm{~m})$, com sucessão soja-milho safrinha, alternado com soja/ trigo e plantio direto com rotação milho/trigo/soja/ aveia/soja/nabo forrageiro, TORMENA et al. (2004) constataram que a escarificação aumentou a macroporosidade e a porosidade total, mas ambos os sistemas possuem quantidade adequada de macroporos. No plantio direto que não foi escarificado, a macroporosidade pode estar associada aos efeitos benéficos da rotação de culturas.

As pequenas diferenças entre os sistemas de culturas utilizados podem ser devido ao curto tempo em que essas culturas foram introduzidas. A amostragem foi realizada no quinto cultivo e, nesse período, nos três sistemas com rotação de culturas, as plantas de cobertura guandu e crotalária foram introduzidas em apenas um cultivo. É esperado que essas plantas de cobertura possam melhorar a qualidade do solo, no entanto, esses efeitos devem ocorrer a longo prazo. NASCIMENTO et al. (2005) não observaram diferenças em atributos físicos de um Luvissolo após a introdução de plantas de cobertura cultivadas por três anos. VOORHEES \& LINDSTROM (1984) observaram mudanças significativas na estrutura do solo sob plantio direto com sucessão de culturas após a escarificação, mas o tratamento sem escarificação e com rotação de culturas teve maior capacidade de suportar restrições físicas, associado ao maior acúmulo de carbono orgânico na camada superficial do solo em relação ao plantio direto escarificado. Também afirmaram que o plantio direto necessita de três a quatro anos para ser considerado como estabelecido, mas REINERT et al. (1990) sugerem um tempo bem maior, superior a 10 anos. Esse tempo deve ser variável com as condições climáticas, o tipo de solo e o histórico das operações de manejo do solo e das culturas e também das culturas implantadas no período.

A macroporosidade diminuiu na taxa de $0,04 \mathrm{~m}^{3} \mathrm{~m}^{-3}$ para cada incremento de $0,1 \mathrm{Mg} \mathrm{m}^{-3}$ na densidade do solo (Figura 1) e foi menor que $0,10 \mathrm{~m}^{3} \mathrm{~m}^{-3}$ quando a densidade superou $1,48 \mathrm{Mg} \mathrm{m}^{-3}$, valor considerado como a densidade crítica para esse Latossolo Vermelho. Nessa densidade, o crescimento da maioria das culturas comerciais sofre restrições físicas, sendo que práticas devem ser adotadas para reduzir a densidade do solo. ARGENTON et al. (2005), em Latossolo Vermelho distroférrico muito argiloso e com teor de matéria orgânica entre 34 e $44 \mathrm{~g} \mathrm{~kg}^{-1}$, observaram que a densidade crítica foi de $1,30 \mathrm{Mg} \mathrm{m}^{-3}$. Eles concluíram que, em solos compactados, devem ser introduzidas plantas com potencial para amenizar esse problema e destacaram que a mucuna cinza cultivada em preparo reduzido foi a que melhor recuperou a qualidade física do solo, apesar de a taxa de recuperação ser pequena após cinco anos de uso dos sistemas propostos.

A condutividade hidráulica saturada $\left(\mathrm{K}_{\mathrm{s}}\right)$ determinada no campo, em outubro de 2001, foi significativamente maior no tratamento R-MAGTS (Rotação - milho / aveia / milho+guandu anão / trigo / soja / trigo). Nesse sistema, foi semeado guandu anão na safra de 1999/2000, enquanto nos demais sistemas as plantas de cobertura foram semeadas há mais tempo (safra de 1998/1999). Outro efeito é a presença da soja, uma leguminosa com baixa relação $\mathrm{C} / \mathrm{N}$ e, portanto, com parte aérea e sistema radicular de fácil decomposição, presente nas safras de 1999/2000 e 2000/ 01 nos sistemas S-TS, R-MAGTS e R-GTSA e ausente no R-CTSAM. Este último teve a menor condutividade hidráulica. No entanto, o sistema R-GTSA também apresentou baixa condutividade hidráulica, talvez pela presença de aveia em pleno florescimento, pois o sistema radicular abundante nessa fase pode obstruir parte dos poros que contribuem para o fluxo de água. Portanto, a presença de leguminosa (guandu e/ou soja) nas últimas safras e a ausência da aveia no estádio do pleno florescimento, durante a medição, parecem contribuir para maior condutividade hidráulica. O coeficiente de variação dessa propriedade, com 12 medições para compor uma média, foi de 102\%.

A curva de retenção de água na camada superficial indica maior umidade na saturação e maior inclinação da curva até próximo de $100 \mathrm{kPa}$, em relação às demais camadas, devido à maior porosidade e melhor 


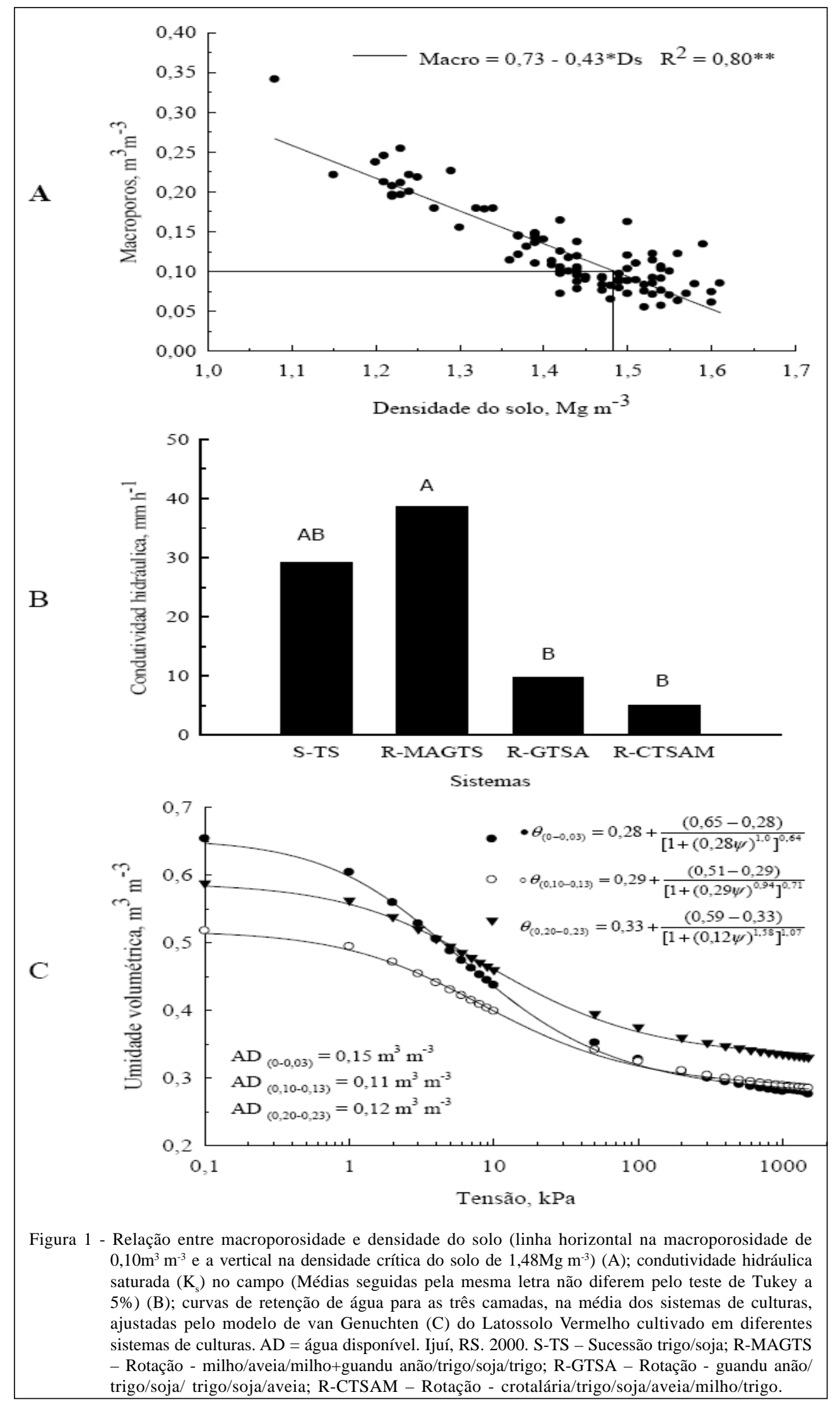

Ciência Rural, v.39, n.1, jan-fev, 2009. 
distribuição do tamanho dos poros. Salienta-se que, nessa camada, ocorre a mobilização do solo pelos mecanismos das semeadoras, onde se observou maior porosidade e aeração e menor densidade do solo. Nos poros responsáveis pela retenção de água entre as tensões de 10 e $1500 \mathrm{kPa}$, o teor de água disponível foi de $0,15,0,11$ e $0,12 \mathrm{~m}^{3} \mathrm{~m}^{-3}$, respectivamente, nas camadas de 0 a $0,03,0,10$ a 0,13 e 0,20 a 0,23m, com redução de $29 \%$ e $19 \%$ da primeira para a segunda e a terceira camada.

A produtividade das culturas variou com o ano (Tabela 3). Devido aos sistemas de sucessão ou rotação serem variáveis no tempo, as comparações de produtividade de cada cultura foram realizadas para as que foram cultivadas na mesma safra. Comparando o sistema S-TS com o R-GTSA, com mesma seqüência de culturas de 1999 a 2001, constata-se que, em 1999 para o trigo e em 2000 para a soja, não houve diferença de produtividade de grãos. Na terceira safra após a introdução da leguminosa, em 2000, a rotação R-GTSA produziu $0,4 \mathrm{Mg} \mathrm{ha}^{-1}$ a mais grãos de trigo do que a sucessão. Entretanto, na quarta safra, em 2000/01, a rotação R-GTSA produziu, aproximadamente, $0,35 \mathrm{Mg}$ $\mathrm{ha}^{-1}$ grãos de soja a menos do que a sucessão S-TS. Essas diferenças não parecem ter uma explicação em função da seqüência de culturas utilizadas, pois, logo após a introdução do guandu, não houve diferença entre os sistemas. Além disso, nas duas safras subseqüentes, as maiores produtividades foram ora para um, ora para outro sistema. No inverno de 1999 e no verão de 1999/2000, o tratamento R-CTSAM produziu, aproximadamente, $0,4 \mathrm{Mg} \mathrm{ha}^{-1}$ a mais grãos de trigo e de soja do que a sucessão S-TS e a rotação R-GTSA. Essa diferença pode ser devido aos benefícios da introdução da crotalária na rotação. No tratamento com a introdução do guandu na terceira rotação (RMAGTS) em 99/2000, não foi observada diferença na produtividade de trigo e soja em relação aos sistemas S-TS e R-GTSA. Na safra de 2001, a produtividade do trigo não diferiu entre os sistemas de rotação utilizados. Assim, o efeito da rotação de culturas sobre a produtividade das culturas subseqüentes pode estar associado com a espécie utilizada na seqüência de culturas. Efeito benéfico foi observado com a introdução da crotalária nos dois cultivos subseqüentes, mas não mais na safra de 2001 na cultura do trigo. O efeito benéfico das leguminosas em consórcio com o milho foi relatado por SPAGNOLLO et al. (2002) em Latossolo Vermelho distroférrico, atribuído, principalmente, ao fornecimento de nitrogênio para o solo.

\section{CONCLUSÕES}

O Latossolo Vermelho cultivado com plantio direto apresenta um grau de compactação elevado, com densidade do solo acima e volume de macroporos abaixo do limite crítico para a classe textural muito argiloso. As maiores limitações ocorrem abaixo da camada de 0 a $0,03 \mathrm{~m}$, pois, nessa camada, apesar das pressões exercidas, a mobilização do solo nas operações de semeadura e adubação em linha aumenta a porosidade e reduz a densidade do solo. Nessa camada, houve maior volume de poros entre a saturação e a capacidade de campo, responsáveis pela aeração do solo, e entre a capacidade de campo e o ponto de murcha permanente, responsáveis pelo armazenamento da água disponível para as plantas.

A produtividade das culturas foi influenciada positivamente na rotação com crotalária, enquanto os demais sistemas não diferiram da sucessão de culturas.

O uso de plantas de cobertura, no terceiro ano, não foi eficiente para reduzir a compactação.

Tabela 3 - Produtividade das culturas utilizadas em cada ano agrícola e produtividade das culturas para cada sistema de culturas na área do campo tecnológico da COTRIJUÍ, município de Ijuí/RS. 1998/2001.

\begin{tabular}{lcccccc}
\hline \multirow{2}{*}{ Tratamento $^{(1)}$} & \multicolumn{5}{c}{ Ano agrícola } \\
\cline { 2 - 7 } & Verão 98/99 & Inverno 99 & Verão 99/00 & Inverno 00 & Verão 00/01 & Inverno 01 \\
\hline S-TS & Soja 2,40 & Trigo 2,60 & Soja 2,94 & Trigo 2,43 & Soja 3,98 & Trigo 2,52 \\
R-MAGTS & Milho 4,82 & Aveia ND ${ }^{(2)}$ & Milho/guandu anão & Trigo 2,36 & Soja 3,86 & Trigo 2,41 \\
R-GTSA & Guandu anão 6,71 & Trigo 2,68 & Soja 2,85 & Trigo 2,85 & Soja 3,63 & Aveia ND \\
R-CTSAM & Crotalária 5,02 & Trigo 3,01 & Soja 3,22 & Aveia 6,80 & Milho 7,60 & Trigo 2,42 \\
\hline
\end{tabular}

(1) S-TS - Sucessão trigo/soja; R-MAGTS - Rotação - milho/aveia/milho+guandu anão/trigo/soja/trigo; R-GTSA - Rotação - guandu anão/trigo/soja/ trigo/soja/aveia; R-CTSAM - Rotação - crotalária/trigo/soja/aveia/milho/trigo.

(2) ND - não determinado.

(3) Massa seca determinada no guandu anão, crotalária e aveia. 


\section{REFERÊNCIAS}

ABREU, S.L. et al. Escarificação mecânica e biológica para a redução da compactação em Argissolo franco arenoso em plantio direto. Revista Brasileira de Ciência do Solo, v.28, n.3, p.519-531, 2004.

ALBUQUERQUE, J.A. et al. Rotação de culturas e sistemas de manejo do solo. I- Efeito sobre a forma da estrutura do solo ao final de sete anos. Revista Brasileira de Ciência do Solo, v.19, n.1, p.115-119, 1995.

ALVARENGA, R.C. et al. Crescimento de raízes de leguminosas em camadas de solo compactadas artificialmente. Revista Brasileira de Ciência do Solo, v.20, n.2, p.319-326, 1996.

ARGENTON, J. et al. Comportamento de atributos relacionados com a forma da estrutura de Latossolo Vermelho sob sistemas de preparo e plantas de cobertura. Revista Brasileira de Ciência do Solo, v.29, n.3, p.425-435, 2005

BAYER, C. et al. Organic matter storage in a sandy clay loam Acrisol affected by tillage and cropping systems in southern Brazil. Soil \& Tillage Research, v.54, n.1, p.101-109, 2000.

BOUMA, J. Influence of soil macroporosity on environmental quality. Advances in Soil Science, v.46, p.1-37, 1991.

CÂMARA, R.K.; KLEIN, V.A. Escarificação em plantio direto como técnica de conservação do solo e da água. Revista Brasileira de Ciência do Solo, v.29, n.5, p.789-796, 2005.

CAMPOS, B.C. et al. Estabilidade estrutural de um Latossolo Vermelho-Escuro Distrófico após sete anos de rotação de culturas e sistemas de manejo do solo. Revista Brasileira de Ciência do Solo, v.19, n.1, p.121-126, 1995.

COLLARES, G.L. et al. Qualidade física do solo na produtividade da cultura do feijoeiro num Argissolo. Pesquisa Agropecuária Brasileira, v.41, n.11, p.1663-1674, 2006.

COSTA, F.S. et al. Propriedades físicas de um Latossolo afetadas pelos sistemas plantio direto e preparo convencional. Revista Brasileira de Ciência do Solo, v.27, n.3, p.527-535, 2003.

ELRICK, D.E. et al. In-situ measurements of hydraulic properties of soils using the Guelph permeameter and the Guelph infiltrometer. In: INTERNATIONAL WORKSHOP ON LAND DRAINAGE, 3., 1987, Columbus. Proceedings... Columbus: Ohio State University, 1987. p.G13-G23.

EMPRESA BRASILEIRA DE PESQUISA AGROPECUÁRIA EMBRAPA. Centro Nacional de Pesquisa de Solos. Manual de métodos de análise de solo. 2.ed. Rio de Janeiro, 1997. 212p.

EMPRESA BRASILEIRA DE PESQUISA AGROPECUÁRIA EMBRAPA. Centro Nacional de Pesquisa de Solos. Sistema brasileiro de classificação de solos. Brasília, 2006. 306p.
JONES, C.A. Effect of soil texture on critical bulk densities for root growth. Soil Science Society of America Journal, v.47, n.6, p.1208-1211, 1983.

KLEIN, V.A. et al. Água disponível em um Latossolo Vermelho argiloso e murcha fisiológica de culturas. Revista Brasileira de Engenharia Agrícola e Ambiental, v.10, p.646-650, 2006.

MORAES, M.H. et al. Efeitos da compactação em algumas propriedades físicas do solo e seu reflexo no desenvolvimento das raízes de plantas de soja. Bragantia, v.54, n.2, p.393-403, 1995.

MÜLLER, M.M.L. et al. Influência da compactação do solo em subsuperfície sobre o crescimento aéreo e radicular de plantas de adubação verde de inverno. Revista Brasileira de Ciência do Solo, v.25, n.3, p.531-538, 2001.

NASCIMENTO, J.T. et al. Efeito de leguminosas nos atributos físicos e carbono orgânico de um Luvissolo. Revista Brasileira de Ciência do Solo, v.29, n.5, p.825-831, 2005.

OLNESS, A. et al. Biosolids and their effects on soil properties. In: WALLACE, A.; TERRY, R.E. (Eds.). Handbook of soil conditioners. New York, NY: Marcel Dekker, 1998. p.141165.

REINERT, D.J. et al. Temporal variation in structural stability induced by tillage. In: EASTERN CANADA SOIL STRUCUTRE WORKSHOP, 1990, Guelph, Ontario. Proceedings... Windsor, Ontario: Canadian Society of Soil Science, 1990. V.1, 236p. p.63-72.

REICHERT, J.M. et al. Compactação do solo em sistema de plantio direto: limites críticos e mitigação. In: COUTO, E.G.; BUENO, J.F. (Eds). Os (des)caminhos do uso da água na agricultura brasileira. Cuiabá: Universidade Federal do Mato Grosso, 2003. 501p.

REICHERT, J.M. et al. Reference bulk density and critical degreeof-compactness for no-till crop production in subtropical highly weathered soils. Soil Till Research, v. online, p.1-13, 2007.

REICHERT, J.M. et al. Compactação do solo em sistemas agropecuários e florestais: identificação, efeitos, limites críticos e mitigação. Tópicos Ciência Solo, v.5 p.49-134, 2007.

ROSENBERG, N.J. Response of plants to the physical effects of soil compaction. Advances in Agronomy, v.16, p.181196, 1964.

SECCO, D. et al. Implications of soil management and compaction state on soil physical properties and soybean yield. Revista Brasileira de Ciência do Solo, v.28, n.5, p.797804, 2004.

SILVA, V.R. et al. Resistência mecânica do solo à penetração influenciada pelo tráfego de uma colhedora em dois sistemas de manejo do solo. Ciência Rural, v.30, n.5, p.795-801, 2000. 
SOWERS, G.F. Consistency. In: BLACK, C.A. et al. (Eds). Methods of soil analysis. Part 1. Madison, Wisconsin: American Society of Agronomy, 1965. p.391-399.

SPAGNOLLO, E. et al. Leguminosas estivais intercalares como fonte de nitrogênio para o milho, no sul do Brasil. Revista Brasileira de Ciência do Solo, v.26, p.417-423, 2002.

TEDESCO, M.J. et al. Análises de solo, plantas e outros materiais. 2.ed. Porto Alegre: Universidade Federal do Rio Grande do Sul, 1995. 174p.

TORMENA, C.A. et al. Propriedades físicas e taxa de estratificação de carbono orgânico num Latossolo Vermelho após dez anos sob dois sistemas de manejo. Revista Brasileira de Ciência do Solo, v.28, n. 6, p.1023-1031, 2004.

UNGER, W.P.; KASPAR, T.C. Soil compaction and root growth: A review. Agronomy Journal, v.86, n.5, p.759766, 1994.
Van GENUCHTEN, M.T. A closed-form equation for predicting the hydraulic conductivity of unsaturated soils. Soil Science Society of America Journal, v.44, p.892-898, 1980.

VEIHMEYER, F.J.; HENDRICKSON, A.H. Soil density as a factor in determining the permanent wilting percentage. Soil Science, v.62, p.451-456, 1948.

VOORHEES, W.B.; LINDSTROM, M.J. Long-term effects of tillage method on soil tilth independent of wheel traffic compaction. Soil Science Society of America Journal, v.48, n.1, p.152-156, 1984.

WOHLENBERG, E.V. et al. Dinâmica da agregação de um solo franco arenoso em cinco sistemas de culturas em rotação e em sucessão. Revista Brasileira Ciência do Solo, v.28, n.5, p.891-900, 2004.

$\mathrm{XU}$, X. et al. Compaction effect on the gas diffusion coefficient in soils. Soil Science Society of America Journal, v.56, n.5, p.1743-1750, 1992. 